\title{
Part 15. Secondary use of unethically obtained data: Fifty shades of grey/ aye/nay
}

SADJ November 2017, Vol 72 no 10 p470 - p472

LM Sykes', WG Evans ${ }^{2}$, F Gani ${ }^{3}$, ZI Vally ${ }^{4}$, HD Dullabh ${ }^{5}$

\section{INTRODUCTION}

On a regular basis, dental practitioners have to make decisions regarding their care of their patients. Previously, dentists did this almost instinctively, drawing upon personal resources such as clinical experience, training, colleagues' opinions, social media and past successes....and failures. Today it is expected that good clinical practice be based on the best and most currently available evidence, obtained by critical appraisal of scientific research and literature, books, journals, internet publications, and participation at continuous education programmes. ${ }^{1}$ This has led to an explosion in research, not all of which is scientifically sound or ethically acceptable. Evidence based dentistry (EBD) evolved as a means of evaluating the science and rigour of research (the focus of the next chapter in this series), while numerous codes of conduct have been developed to try to ensure ethical standards.

Clinical research aims to "develop generalizable knowledge that will improve health, advance treatment modalities, and / or increase understanding of human biology". ${ }^{2}$ To achieve these goals the investigations often rely on study participants, who may be put at risk of harm. If fifty people were asked what makes clinical research ethical, there would probably be as many different answers. The most common response is usually the essentiality of informed consent, yet Emmanuel et al. argue that this agreement alone is not sufficient. ${ }^{2}$ They proposed that seven requirements need to be met to ensure ethical integrity. These are: Value, (enhancement of health or knowledge); Scientific validity; Fair subject selection; Favourable risk: benefit ratio; Independent review; Informed consent; and Respect for enrolled subjects. ${ }^{2}$

1. Leanne M Sykes: BSc, BDS, MDent (Pros), Dip Res Ethics (Irensa), Dip Forensic Odont. Department of Prosthodontics, University of Pretoria.

2. William G Evans: BDS, Dip Orth. Department of Orthodontics, University of Witwatersrand.

3. Fatima Gani: BDS, MSc (Oral path). Department of Prosthodontics, University of Pretoria.

4. Zunaid I Vally: BDS, MDent (Pros), Department of Prosthodontics, University of Pretoria

5. Hermant D Dullabh: BChD, MSc (Dent), MDent (Pros), Department of Prosthodontics, University of Pretoria

\section{Corresponding author}

Leanne M Sykes:

Department of Prosthodontics, University of Pretoria.

E-mail: leanne.sykes@up.ac.za

\section{HISTORICAL EXAMPLES OF UNETHICAL RESEARCH IN DENTISTRY}

Gustaffson et al. conducted a cariology study that spanned over more than ten years, from 1945-1953. Their aim was to determine the relationship between diet, frequency of sugar intake and dental caries. Different groups of mentally-deficient children were fed sweets, carbohydrates, chocolates and toffees in varying amounts, for a five year period. Some benefitted from the inclusion of vitamin and mineral supplements, while others did not. Results showed a definite correlation between the type of sugar, the frequency of consumption, the amount and time of day when it was ingested and the prevalence of dental caries. ${ }^{3}$ Whilst the results are instructive, the use of a defenceless and uninformed sample of children exceeds the bounds of ethical practice.

In the 1940s, state officials in Massachusetts implemented fluoridation studies surreptitiously at two schools for mentally retarded children. Minors were give radioactive fluoride isotopes without their assent or consent of their parents. ${ }^{4}$ Although it is now widely accepted that fluoride plays a beneficial role in preventing caries, this was unknown at the time of the investigation. Not only were vulnerable children, who lacked the capacity to understand or object, unwittingly exposed to fluoride, but parents were not consulted or asked for permission to allow the participation of their child. In addition, the researchers carried out the intervention without knowing or considering the possible systemic side effects. It is concerning, that eighty years later Colgate conducted several studies to investigate the efficacy of their recently launched Sugar-acid neutraliser toothpaste. Two of these were carried out on Chinese scholars and spanned a six month period. The children were divided into three groups. The first group received fluoride and arginine toothpaste, the second received a fluoridated toothpaste and a placebo group received toothpaste with neither fluoride nor arginine. This resulted in 298 participants being deprived of effective fluoride toothpaste which is considered the gold standard in oral hygiene. ${ }^{5} \mathrm{~A}$ key principle in ethics in research is that it should never include a placebo group when there is an effective product available. The company encountered international obloquy for what was considered to be an unethical study. ${ }^{6}$

Friedman reported on the millions of third molar teeth that have been "prophylactically extracted" in order 
to prevent possible later complications. This has led to numerous patients being subject to unnecessary surgical procedures, with associated pain, discomfort, swelling, bleeding, bruising and even worse, temporary or permanent paraesthesia of the tongue, lip or cheeks as a consequence of nerve injury. ${ }^{7}$ This practice of wisdom tooth removal was based on specious and unsound studies, which were thus automatically also unethical. ${ }^{8}$

The American Dental Association (ADA) has strongly condemned the many studies in which patients had sound amalgam restorations removed and replaced with other plastic fillings in order to "remove their bodies of toxic mercury". The ADA comment that when such treatment is performed solely at the recommendation of the dentist, it is improper and unethical. ${ }^{9}$ Some of these papers reported on studies which subjected patients to additional blood tests before and after removal of the amalgam. The authors then attempted to justify findings that did not support their contentions by stating that "During initial exposure to mercury (i.e. on amalgam placement) the body hosts an immune response to try deal with the toxicity and many test values will be high. However after prolonged exposure the systemic challenge decreases and so some tests show a decline. During this time the patient will experience chronic conditions which could even include DNA damage and cancer."10

These examples raise the question of whether it is ethically sound to make use of data that was obtained in an unethical manner.

\section{OPINIONS}

A number of dental colleagues from all sectors, with widely differing experiences were asked the following question: "Do you think it is ethically acceptable to re-use data or information gained from unethically conducted studies?"

1. My gut tells me No. But I guess if the information is already out there and I use it but disclose in my publication that it was unethically obtained, that will be OK.

2. Yes, the harm has already been done, we can't change that, so why waste the material if it can help others for the future?

3. No, it will make others think it's Ok to do unethical research if the results end up being useful to lots of people.

4. No, I don't want readers to think I agree with this type of study. It may also give others ideas and they may try to copy and do similar unethical investigations and also get away with it.

5. No. That's a tough one. Then you could get a "friend" to do your unethical research and you later come and use the data.

6. No. If the information was obtained unethically then it can't be used. But a lot of knowledge we use today is based on previous unethical studies, so perhaps God in his wisdom allowed these to happen before we became more ethically conscious.

7. Yes. It may not have been ethical, but the results are still valid. I know certain countries do lots of unethical studies, but this gives us a wealth of information.

8. Yes. How ethical is it to take a dog and put it down just to see how an implant will behave in the mouth, yet this is the norm?
9. Yes. So wear a denture or nothing if you want to be ethical and don't come asking for restorations or implants if you lose your teeth.

10. No, because it was unethical in the first place, so, how can you be ethical to use it yourself? It's like accepting stolen goods, as long as you didn't steal them.

11. Yes. There were a lot of old unethical studies but they were all good for science. But sadly not good for ethics, but we learnt a lot from them regardless.

12. Of course not. No. It is unacceptable.

13. Isn't that what the Nazis did - it may not be ethical but it is still valid data.

14. I will definitely use the data because it is still valuable information if it was scientifically done. Despite being unethical.

15. No. Most definitely no. If you know it was unethical there is no way you must use it. If you are unaware of this then it is alright.

16. Yes. Is it ethical to waste information that has already been gained at such a high cost?

\section{DISCUSSION}

Not only do ethical issues generate widely diverse opinions between respondents, but many battled to even formulate a definite personal stance. This informal survey amongst a random sample of dental colleagues revealed the ambiguities and uncertainties associated with medical ethics as was evidenced by the many "Yes buts, maybes, only ifs, " with very few definitive "Aye or Nay" responses. The Declaration of Helsinki ${ }^{11}$ clearly requires that any research not conducted according to its provisions should not be published. ${ }^{12}$ However, this creates the impression that the issue is "black-and-white", when quite clearly it has emerged that there are various shades of grey in between. If you attempt to resolve this uncertainty by evaluating the research in terms of the requirements set out in the Nuremburg Code for Ethical Clinical Research, it would clearly not be acceptable. The Code specifies that it is the investigator's responsibility to gain voluntary informed consent from all study participants, the investigator must guarantee the scientific soundness of the study design, avoid inflicting any unnecessary harm or suffering, assess the risks versus the benefits, make provision for ongoing health care after completion of the study, and ensure that subjects are aware of their rights, and have the means to withdraw from the study at any time..$^{13}$ It could be argued that this policy was established as a blueprint to guide future research, and the debate is over re-use of data that has already been collected. As such the "new" researchers have no control (or liability?) over any of the above stipulations.

Perhaps publishers also need to assume some of the responsibilities in the endeavour to prevent unethical research by having stricter submission requirements. Instead of merely refusing to publish contentious clinical studies, the editors could insist that papers contain a section on ethical methodology that is as detailed as is the scientific description. In this the researchers would be required to "display evidence that they had given explicit and careful consideration to all ethical issues. This would give the journal more standing than their refusal to publish, and would help build up a body of expertise in dealing with ethically complex research settings". ${ }^{2}$ The editors 
would still reserve the final right to refuse publication of any research deemed to be unethical. Here again they may need to make value judgements based on the "reasonable man" rule, and the principles of beneficence, non-maleficence, autonomy and justice. ${ }^{14}$

\section{CONCLUSION}

There is no correct answer to this debate, although it seems that many people are of the opinion that the data should not be wasted no matter how grievously it was obtained. One recommendation may be to first establish whether the investigation was scientifically sound and that the data produced is valid. Thereafter it may be used but with a strongly worded covering statement to the effect that: "The researchers acknowledge that the original study is unacceptable by currently-held ethical standards. They do not condone this investigation but after interrogation of the results found the data to be of high quality, reliable and valid. As such, the merits and strong points of the paper were re-used and quoted in the follow up research". To paraphrase the common idiom, do not discard something of potential value in your fervour to be rid of something useless or deplorable associated with it... the "baby and the bath water" conundrum.

\section{References}

1. Kanduluru A, Naganandini S, Aradhya S. Evidence based dentistry. IJOCR. 2013;1(1):14-9.

2. Emmanuel E, Wendler D, Grady C. What makes clinical research ethical? JAMA. 2000;24(31):2701-11.

3. Gustafsson BE, Quensel CE, Lanke LS, et al. The Vipeholm dental caries study; the effect of different levels of carbohydrate intake on caries activity in 436 individuals observed for five years. Acta Odontol Scand. 1954;11(3-4):232-64.

4. History of Fluoride. Unethical fluoride tests in Massachusetts: Accessed at : www.fluoride-history.de. Accessed on : 01-11-2016.

5. Shaw D, Naimi-Akbar A, Astvaldsdottir A. The tribulations of toothpaste trials: Unethical arginine dentifrice research. BDJ. 2015;219:567-9.

6. Sykes LM, Brandt PD, Evans WG. The ethics of research: Part 4: Safeguarding the scientist, protecting the participants. SADJ. 2016;71(9):412-4

7. Friedman JW. The prophylactic extraction of third molars: a public health hazard. Am J Public Health. 2007;97(9):1553-9.

8. Sykes LM, Evans WG, Brandt PD. The research focus question: Part 6: Finding the flaws, explaining the errors, and suggesting solutions. Submitted to SADJ. 2016

9. ADA. Section 5 - Principle of veracity ("truthfulness") Accessed at: http://www.ada.org/en/about-the-ada/principles-of-ethics-codeof-professional-conduct/veracity. Accessed on: 24-10-2016.

10. Huggins HA, Levy TE. Uninformed Consent. The Hidden Dangers in Dental Care. Hampton Road Publishing, editor. Hampton;1999.

11. World Medical Organization. The Declaration of Helsinki. Br Med J. 1996;313(7070):1448-9.

12. Zion D, Gillam L, Loff B. The Declaration of Helsinki, CIOMS and the ethics of research on vulnerable populations. Nature Medicine. 2000;6(6):615-7.

13. Macrae D. The Council for International Organizations and Medical Sciences (CIOMS) Guidelines on Ethics of Clinical Trials. The Proceedings of the American Thoracic Society. 2007;4:176-9.

14. Beauchamp T, Childress JF. Principles of Biomedical Ethics. Oxford University Press, editor. New York; 2001.

\section{6) Gy (y) JONUSINNEW ZEALANDANDHAVEA LEESTMETO ENM The Dentists love your smile}

\section{NEW ZEALAND PASSENGER ARRIVAL CARD}

Rated in the top ten safest countries in the world - New Zealand is the place where you can enjoy beaches, parks, award-winning wine, world-class restaurants and a range of cultures right on your doorstep - literally.

New Zealand has that perfect combination of big city and country town all rolled into one. With a great community feel, excellent schooling and a thriving economy - New Zealand really is a place that you can call home.

With 91 practices nationwide there are opportunities everywhere to enjoy the lifestyle you want, plus enjoy:

(D) Excellent salary, standard of living and work/life balance

(v) Lucrative earning potential in smaller towns

(d) Career advancement and development within the Lumino Group

1 We need talented

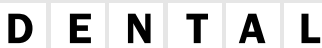
C L I $\quad \mathbf{N}$

to start

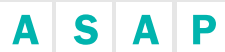

2 For further information:

\begin{tabular}{lll|l|l|l|l|l|l|l|l|l|l|l|l|l|l|l|l|l|l} 
C & A & $\mathbf{R}$ & $\mathbf{E}$ & $\mathbf{E}$ & $\mathbf{R}$ & $\mathbf{S}$ &. & $\mathbf{L}$ & $\mathbf{U}$ & $\mathbf{M}$ & $\mathbf{I}$ & $\mathbf{N}$ & $\mathbf{0}$ &. & $\mathbf{C}$ & $\mathbf{0}$ &. & $\mathbf{N}$ & $\mathbf{Z}$ \\
\hline
\end{tabular} 